\title{
Bandwidth Extension of Ultra-wideband Microstrip Antenna Using Metamaterial Double-side Planar Periodic Geometry
}

\author{
Ehab K. I. HAMAD, Gehad NADY \\ Dept. of Electrical Engineering, Faculty of Engineering, Aswan University, Aswan 81542, Egypt \\ e.hamad@aswu.edu.eg, gehadnady2020@gmail.com \\ Submitted August 16, 2018 / Accepted January 1, 2019
}

\begin{abstract}
A compact extended bandwidth UWB microstrip antenna is designed utilizing metamaterial (MTM) doubleside planar periodic structures. The proposed antenna comprises two MTM unit cells made by etching X-shaped slots on the main radiating patch, and four slots at the vertices of a square periodically repeated in two-dimensions on the ground plane. The proposed antenna fabricated on $1.6 \mathrm{~mm}$ low-cost FR4 substrate is compact, measuring $27.6 \times 32 \mathrm{~mm}^{2}$, with relative permittivity of 4.5 and loss tangent of 0.02. It has a broad bandwidth covering 3.2 to $23.9 \mathrm{GHz}$, with a peak gain of $6.2 \mathrm{~dB}$ at $8.7 \mathrm{GHz}$. The antenna has good radiation characteristics for UWB applications. The measured return loss $\left(S_{I I}\right)$ of the test antenna fabricated for this study was in good agreement with the simulated results.
\end{abstract}

\section{Keywords}

Antennas, metamaterial, microstrip antenna, MTM, periodic structure, ultra-wideband (UWB)

\section{Introduction}

Ultra-wideband (UWB) technology is a type of wireless communication technology which has received much attention in a wide range of applications. With wireless communications experiencing vast growth recently, wide bandwidth antennas are always in demand because different UWB applications can be addressed using a single antenna. Microstrip patch antennas have long been used in a wireless communication because of their low cost, light weight, simplicity and low profile - features that make them attractive for various applications [1], [2]. Many approaches have been used to enhance the bandwidth of patch antennas, such as by obtaining good impedance matching between the feeding line and the radiating element [3], [4]. Another approach involves electromagnetic band-gap structures coupled to the main patch [5].

In the 1980s, Yablonovitch [6] and John [7] produced the first 3-D periodic structures that were electromagnetic band gap (EBG) structures constructed from periodic lat- tices. In recent years, patch antennas have been incorporated with EBG structures to enhance antenna performance by surface-wave suppression, and are used as ground planes in low profile designs [8], [9]. When some of such structures are engraved, the result is generally an equivalence of capacitance or inductance. For example, if we want to make series capacitors, the easiest way is to engrave a slit on the patch which then performs like a series capacitor. On the other hand, the EBG technique enables enhancement of patch antenna bandwidth besides improving their radiation pattern, increasing gain, and reducing the side lobe and back lobe levels [10-12]. There is still ongoing research for solutions to improve the bandwidth for patch antennas [13]. One such approach is the incorporation of MTM in either the top or bottom layer of the antenna to exploit the unusual properties of metamaterials to change certain of the antenna features.

In this paper, the proposed antenna covers the C-band, $\mathrm{X}$-band, and Ku-band. The overall size of the antenna is small compared to others presented in [14], [15], and has impedance bandwidth wider than that proposed in [16-18]. Through this study, left-handed metamaterials (LHM) in two-dimensional (2D) configurations based on two different types of unit cells are presented. The first cell is etched on the radiating patch and the other cell is implemented on the ground plane. The cell incorporated on the patch is an X-shaped etching, repeated and arranged in two dimensions with each cell connected to the surrounding cells as illustrated in Fig. 1(a). The cell integrated to the ground appears as a square shape slotted $45^{\circ}$ at its corners, with each square isolated from surrounding cells as depicted in Fig. 1(b). The aim of this paper is to enhance further the bandwidth and gain in a conventional microstrip antenna by applying a MTM periodic structure on the patch and on the ground plane. The proposed structure is simple in design, cost effective, and compact in comparison with most of the previous configurations.

This paper is organized as follows: the introduction appears in Sec. 1, the MTM unit cell configuration is illustrated in Sec. 2. The proposed antenna design and configuration are presented in Sec. 3. The parametric study for the proposed antenna is described in Sec. 4. Section 5 discusses 


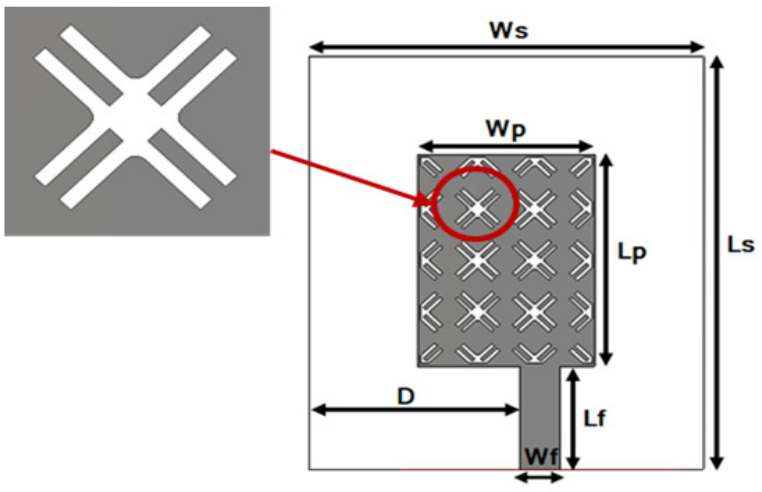

(a) Top view

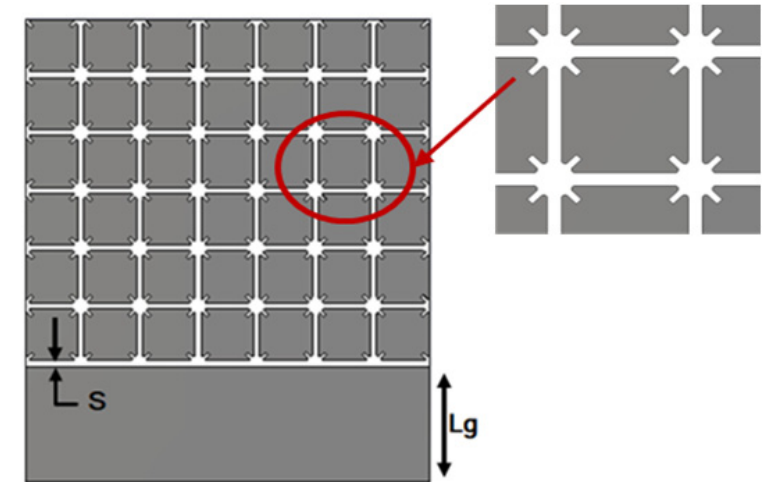

(b) Bottom view

Fig. 1. Geometry of the proposed UWB antenna.

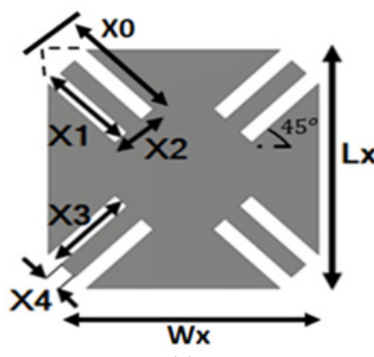

(a)

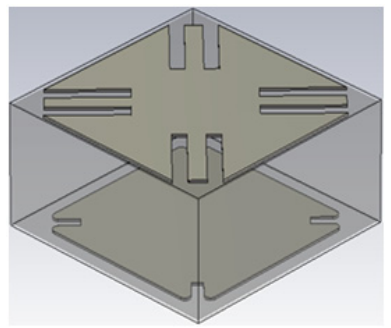

(c)

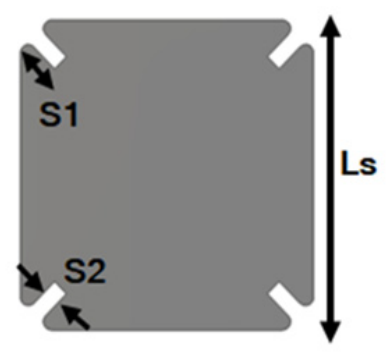

(b)

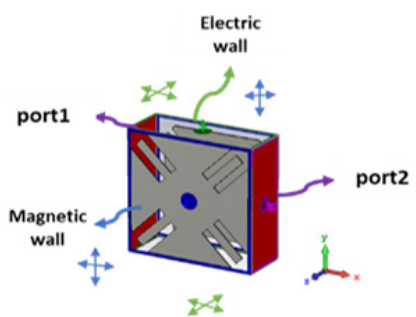

(d)

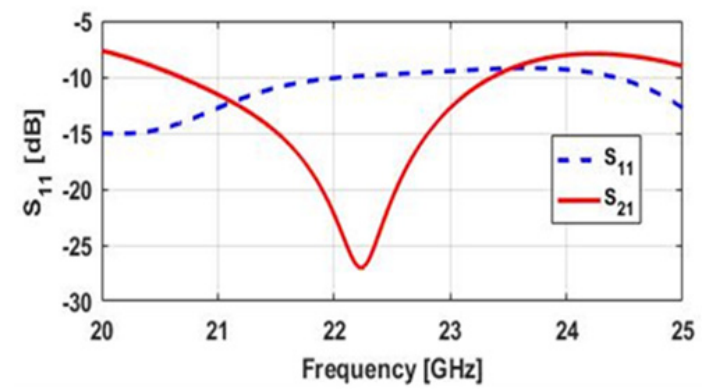

(e)

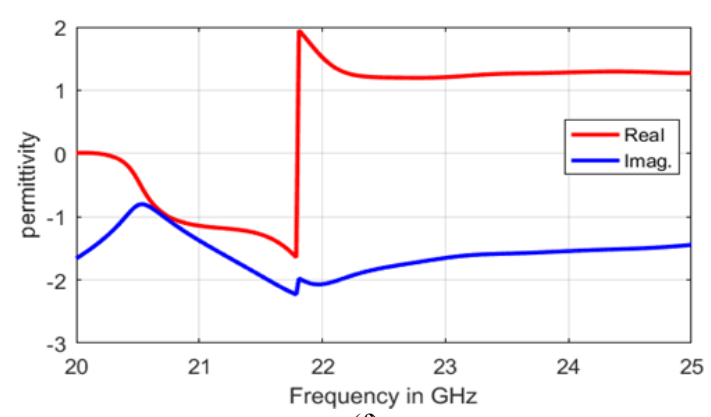

(f)

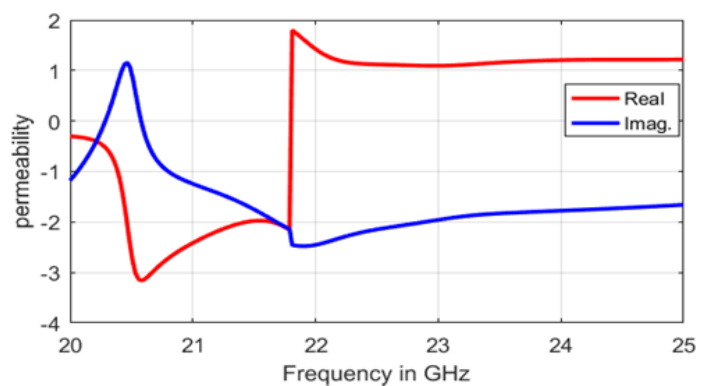

(g)

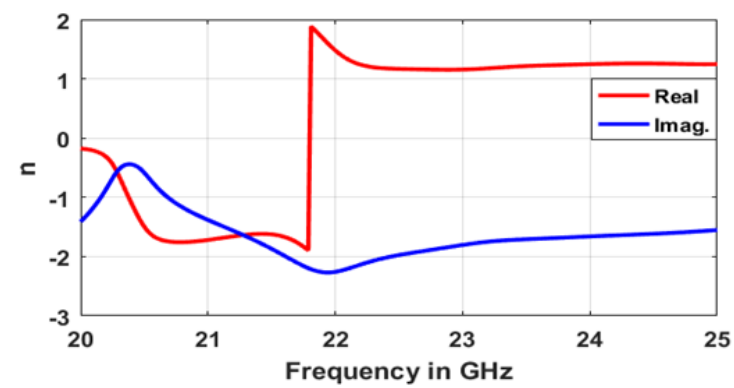

(h)

Fig. 2. MTM unit cells: (a) X-shaped cell, (b) square shaped cells with cleft vertices, (c) 3D view of the first and second unit cells aligned vertically, (d) cell modeling on CST with boundary setup, (e) S-parameter of MTM unit cell configuration of (c), (f) permittivity, $\varepsilon_{\mathrm{r}},(\mathrm{g})$ permeability $\mu_{\mathrm{r}}$, and (h) refractive index, $n$.

the measured data obtained and their comparison with the simulated values. Finally, Section 6 concludes this work.

\section{MTM Unit Cell Design and Operation}

Figure 2 illustrates the geometry of the proposed MTM unit cells. Figure 2(a) depicts the first unit cell of an X- or star-shape. The second unit cell forms a square with its vertices cleft as shown in Fig. 2(b). To clearly understand how both cells work together, a 3D unit cell was constructed on FR4 substrate of $1.6 \mathrm{~mm}$ thicknesses, with the first unit cell on top and the second cell at the bottom. Both cells were positioned on both sides of the 
substrate with corresponding top and bottom cells in good vertical alignment as shown in Fig. 2(c). The 3D unit cell was modeled on the CST software based on time domain solver and all cell dimensions were optimized to resonate at $22 \mathrm{GHz}$, which was close to the higher edge of the desired frequency range of the UWB antenna proposed in this paper to extend the band width as much as possible.

To investigate the behavior of the proposed unit cell as a symmetric periodic structure, two waveguide ports were used and perfect electric and perfect magnetic boundary conditions were set as illustrated in Fig. 2(d). The boundary conditions are appeared either in the walls of the wave-guiding system or along the propagation direction. The scattering matrix analysis in the time domain is used in this analysis, which is able to produce broadband results. The set of transfer function between the input and output ports of the unit cell is capable to illustrate its macroscopic performance as an inhomogeneous symmetric periodic structure, where the appearance of higher order modes is systematically ignored [19].

The simulated S-parameters of the modeled MTM unit cell on CST MWS are shown in Fig. 2(e). Based on the algorithm presented in [20], the relative permittivity and permeability characteristics as well as the refractive index of the modeled unit cell are extracted from the scattering parameters as illustrated in Figs. 2(f), (g), and (h), respectively. It can be observed that the proposed cell behaves as a MTM structure with negative index of refraction at the designed frequency. The optimized unit cell dimensions in mm were as follows: $L_{x}=4, W_{x}=4, X_{\mathrm{o}}=1.96, X_{1}=1.39$, $X_{2}=0.8, X_{3}=1.4, X_{4}=0.3, L_{\mathrm{S}}=3.6, S_{1}=0.7, S_{2}=0.2$. Following this, 2D periodic patterns formed by the recurrence of the first unit cell along two axes were incorporated on the patch, keeping each unit cell connected with all other cells surrounding it. Another 2D periodic geometry obtained by repeating the second unit cell was integrated in the ground plane. Here, each cell was isolated from all surrounding cells by slots of $0.4 \mathrm{~mm}$ width. The design configuration using these $2 \mathrm{D}$ periodic structures were investigated in detail to design our extended bandwidth UWB antenna, as described in the next section.

\section{Antenna Design and Configuration}

Figure 1 shows different perspectives of the proposed antenna structure. Commercial $27.6 \times 32 \mathrm{~mm}^{2}$ FR4 of $1.6 \mathrm{~mm}$ thickness, 4.5 relative permittivity and 0.02 loss tangent was selected as the substrate. A microstrip inset feed in the patch is used to attain superior impedance matching between the transmission line and the patch. Thus, the patch returned insignificant amount of incident energy at its operating frequency. Thereafter, the concept of metamaterial-based periodic structure was explored to achieve ultra-wideband performance and diminutive antenna size. One X-shaped unit cell was designed and then repeated periodically in two-dimensions for embedment in the patch. Another unit cell, a square with cleft vertices, was designed and then converted into a $6 \times 7$ planar periodic structure for incorporation in the ground plane. The electric field which was perpendicular to the surface of the antenna excited the electrical responses of the MTM unit cells. Suitably loaded, the 2D periodic patterns increased the current path within the patch area. The values of the antenna parameter were as follows: $W_{\mathrm{S}}=27.6, L_{\mathrm{S}}=32$, $W_{\mathrm{P}}=12.4, L_{\mathrm{P}}=16.4, L_{\mathrm{F}}=8, W_{\mathrm{F}}=2.8, L_{\mathrm{g}}=8, D=14.8, S=$ 0.4 (all dimensions in $\mathrm{mm}$ ). The patch was excited using a microstrip feed line with a width of $2.8 \mathrm{~mm}$ and length of $8 \mathrm{~mm}$ to ensure $50 \Omega$ impedance matching. The metals of the feed line and of the ground plane underneath the feed line were not etched to protect the transmission consistency of the input energy. The 2D patterns in the upper patch and ground plane in this antenna design were coupled to form a capacitive-inductive equivalent circuit. Radiation along the direction of the plane of the patch increases when the backward wave induced is travelling along the plane of the patch. This antenna was designed to enhance the horizontal radiation, and also to expand the bandwidth by coupling the ground plane with the substrate and pattern in the radiating patch. The design and simulation were completed under a CST Microwave Studio environment.

\section{Parametric Study}

To examine the effects of the geometric variables in our design, a full parametric dimension study was performed in order to nominate parameters for evaluation, specify each parameter range, define the design limitations, and analyze the results of each parameter variation. When the configurations were generated, we evaluated our simulations before further refining the parameters according to the design constraints until the results were satisfactory. First, the feed line position with respect to the patch was optimized to match the transmission line to the patch perfectly. Then, the ground plane length was adjusted to obtain the widest possible bandwidth. The optimized design without further enhancement by additional techniques is shown in Fig. 3(a). After that, each type of cells has been studied individually. The first cell (X-shape) was incorporated in the patch periodically as shown in Fig. 3(b) to give an acceptable response over the band from 3.2 to $12.3 \mathrm{GHz}$. Then the second cell was integrated in the ground plane as depicted in Fig. 3(c) to cover a frequency range from 3.2 to 17.7 GHz. The corresponding $\mathrm{S}_{11}$ for each case is displayed in Fig. 3(d).

The novel MTM unit cells described in Sec. 2 were then incorporated on to both sides of the antenna to further extend the operating frequency range of the proposed UWB microstrip antenna. To ensure that the MTM unit cells used in the antenna behave as a symmetric periodic structure; the same boundary conditions described in Sec. 2 are employed where two waveguide ports were used and perfect electric and perfect magnetic boundary conditions were set. To understand the effect of the parameters used to improve the impedance bandwidth, we carried out a study where we varied various parameters in the MTM unit cell that had all 
the parameters installed, changing only one parameter at a time. The parametric studies and surface current distribution helped us to understand the influence of the MTM cell's dimensions on the antenna performance. The depth of the cleft in the vertices of the MTM unit cell implemented in the ground $\left(S_{1}\right)$ in conjunction with the fork in the vertices of the MTM unit cell implemented in the patch $\left(X_{1}\right)$ depicted in Fig. 2(a) and (b) were investigated here to determine the optimal values for best performance. Figure 4 shows results for $S_{1}=0.5 \mathrm{~mm}$ and various values of $X_{1}$, while Figure 5 gives the results for $S_{2}=0.7 \mathrm{~mm}$. As the cleft depth $\left(S_{1}\right)$ decreased, some of the frequencies were found to be out of range. The same outcome was observed when the value of $X_{1}$ was increased above $1.4 \mathrm{~mm}$. The line width and slot width were limited by the technology available, which was $0.2 \mathrm{~mm}$. The optimal value obtained for $X_{1}$ was $1.4 \mathrm{~mm}$.

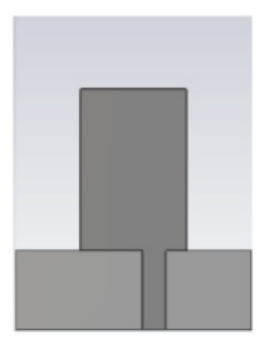

(a)

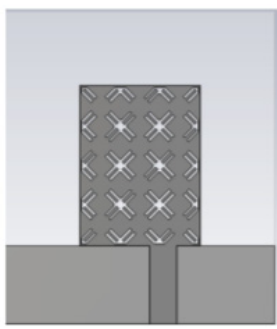

(b)

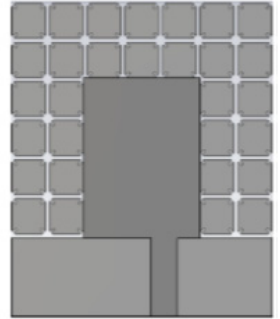

(c)

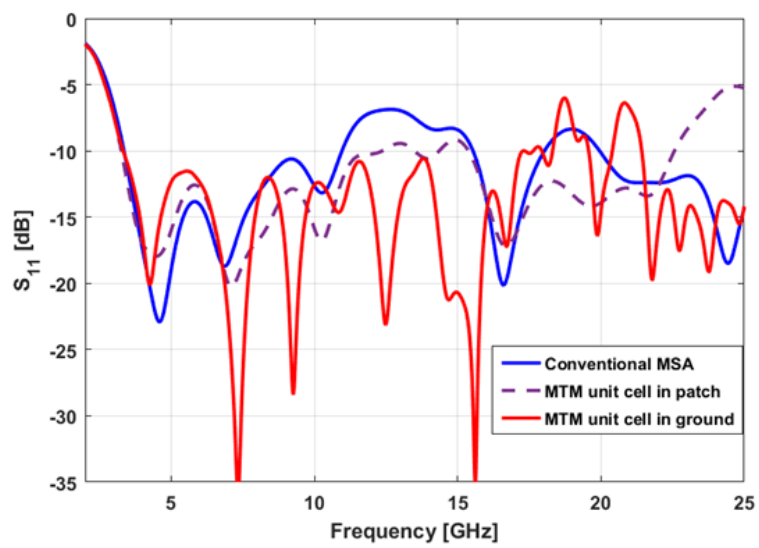

(d)

Fig. 3. (a) Conventional MSA without further enhancement, (b) MSA when creating the 2D MTM unit cells only in patch, (c) when implementing the 2D MTM unit cells only in the ground, and (d) the corresponding S-parameters.

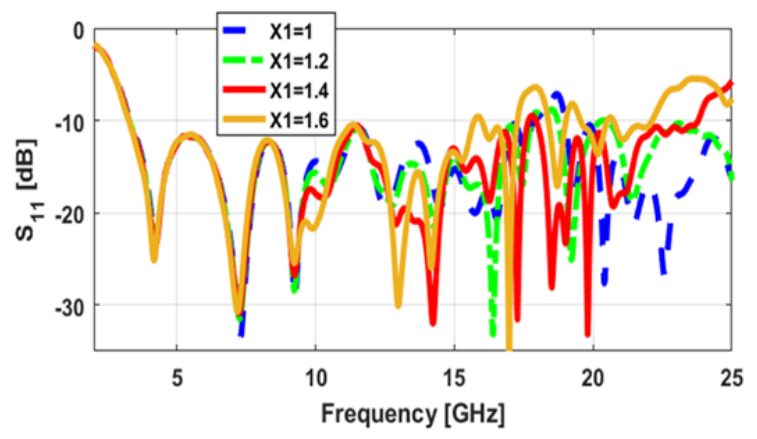

Fig. 4. Effect of varying the length $\mathrm{X}_{1}$ at $S_{1}=0.5 \mathrm{~mm}$.

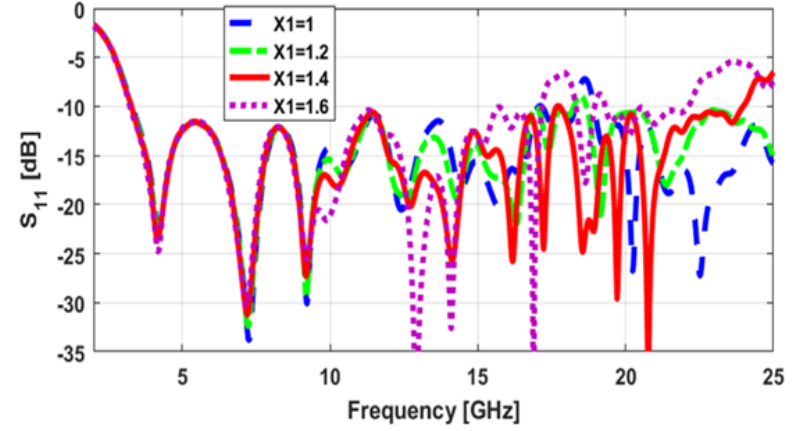

Fig. 5. Effect of varying the length $X_{1}$ at $S_{1}=0.7 \mathrm{~mm}$.

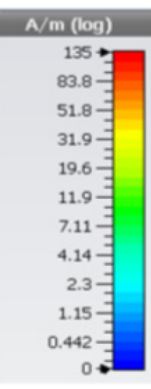

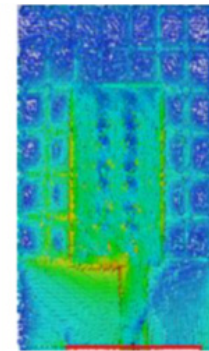

(a) $4 \mathrm{GHz}$

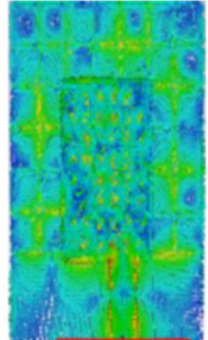

(a) $13 \mathrm{GHz}$

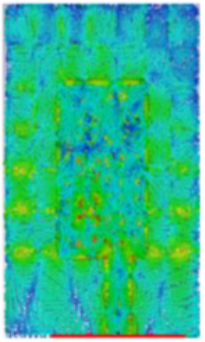

(a) $21 \mathrm{GHz}$

Fig. 6. Surface current distribution on the top layer of the proposed antenna.

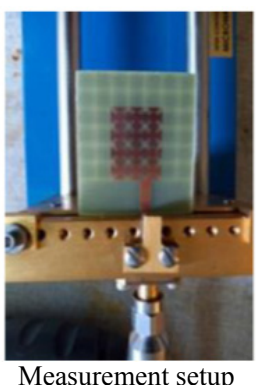

Measurement setup

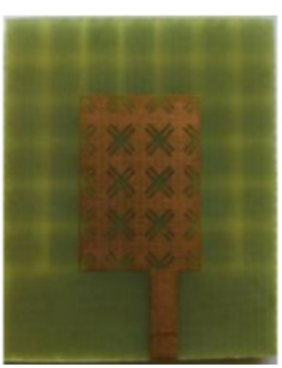

Top view

(a)

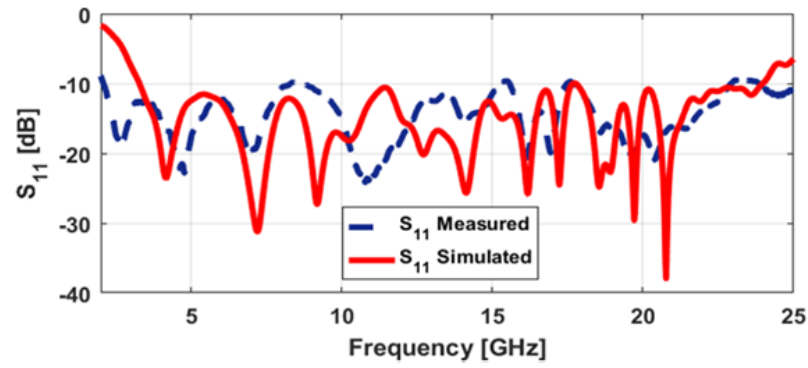

(b)

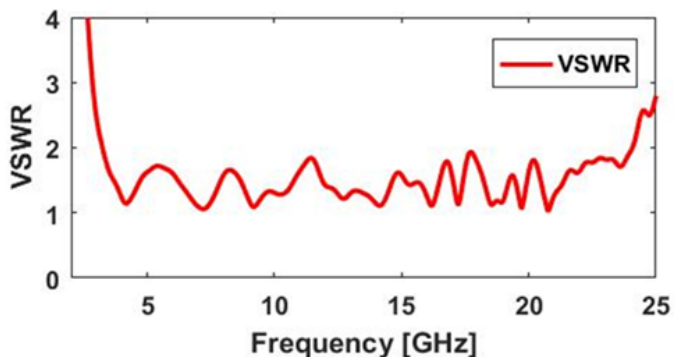

(c)

Fig. 7. Proposed UWB microstrip antenna: (a) Photographs of the fabricated model, (b) $\mathrm{S}_{11}$ curves; simulated and measured, (c) voltage standing wave ratio (VSWR). 
The distribution of the surface current on the top layer of the proposed antenna is displayed in Fig. 6 for different selected frequencies of $4 \mathrm{GHz}, 13 \mathrm{GHz}$ and $21 \mathrm{GHz}$. It was observed that at the lower frequency $(4 \mathrm{GHz})$, the surface current was concentrated mostly at the near edge of the radiating element with the radiation being more prominent there. At frequencies 13 and $21 \mathrm{GHz}$; the far edge of the radiating element contributed considerably to the radiation.

\section{Measurements and Discussion}

The proposed antenna was fabricated using a CNC machine on commercially available low-cost FR4 substrate and tested successfully using the Agilent Technologies Microwave Network Analyzer. The dimensions of the fabricated model were as stated in Sec. 3. Figure 7(a) shows a photograph of the fabricated antenna prototype as well as the measurement setup. The measured S-parameters compared to the simulated counterparts are illustrated in Fig. 7(b). It can be seen that the simulated and measured results were generally in good agreement although there were some discrepancies between the experimental and simulation results due to manufacturing tolerances and variations in material characteristics of the sample used. The voltage standing wave ratio (VSWR) defined as $(1+|\Gamma|) /(1-|\Gamma|)$, where $\Gamma$ indicates the reflection coefficient, would serve as a good indicator as to whether the system worked efficiently over the range of operating frequencies. The fabricated test antenna maintained VSWR values lower than 2 over the whole operating frequency range as shown in Fig. 7(c). This could be considered a good reference value for engineering applications to ensure acceptable impedance matching by using the concepts of edge feed.

The fabricated antenna was compatible with a wide range of frequency, ranging from $3.2 \mathrm{GHz}$ to over $23.5 \mathrm{GHz}$. It had a good impedance bandwidth of $173 \%$, as calculated by the following equation:

$$
B W \%=\frac{\left(f_{\mathrm{H}}-f_{\mathrm{L}}\right)}{f_{\mathrm{C}}} \times 100 \%
$$

where $f_{\mathrm{H}}$ is the upper band frequency, $f_{\mathrm{L}}$ is the lower band frequency base on $-10 \mathrm{~dB}$ criteria, and $f_{\mathrm{C}}$ is the center frequency with the relation $f_{\mathrm{C}}=\left(f_{\mathrm{H}}+f_{\mathrm{L}}\right) / 2$.

The 3-D radiation patterns of the proposed antenna at various selected frequencies of $4.6,10.2,17$, and $23.6 \mathrm{GHz}$ are presented in Fig. 8. Because of the left-handed transmission characteristics, maximum radiation occurred over the horizontal direction in lieu of the vertical direction as in case of the conventional patch antenna. It was noted that at the lower frequencies such as $4.6 \mathrm{GHz}$, the maximum radiation was along the vertical direction with some tilt towards the $x y$-plane. At the higher frequencies, however, the maximum concentration of the radiation was along the $x$ direction as in the cases of 7 and $10.2 \mathrm{GHz}$. At the highest frequencies, the radiation conformed to the higher order modes that were responsible for the splitting of radiation lobe. Hence, at $10.2 \mathrm{GHz}$, the main beam splitting was found with the direction of radiation intensity along the $x$ direction. On the other hand, at frequencies 17 and $23.6 \mathrm{GHz}$, the maximum radiation began to be oriented vertically again. The proposed antenna showed a stable radiation pattern over the entire frequency range of interest. The radiation pattern was found to be almost omnidirectional in the H-plane, which is of most interest for wireless communication systems.

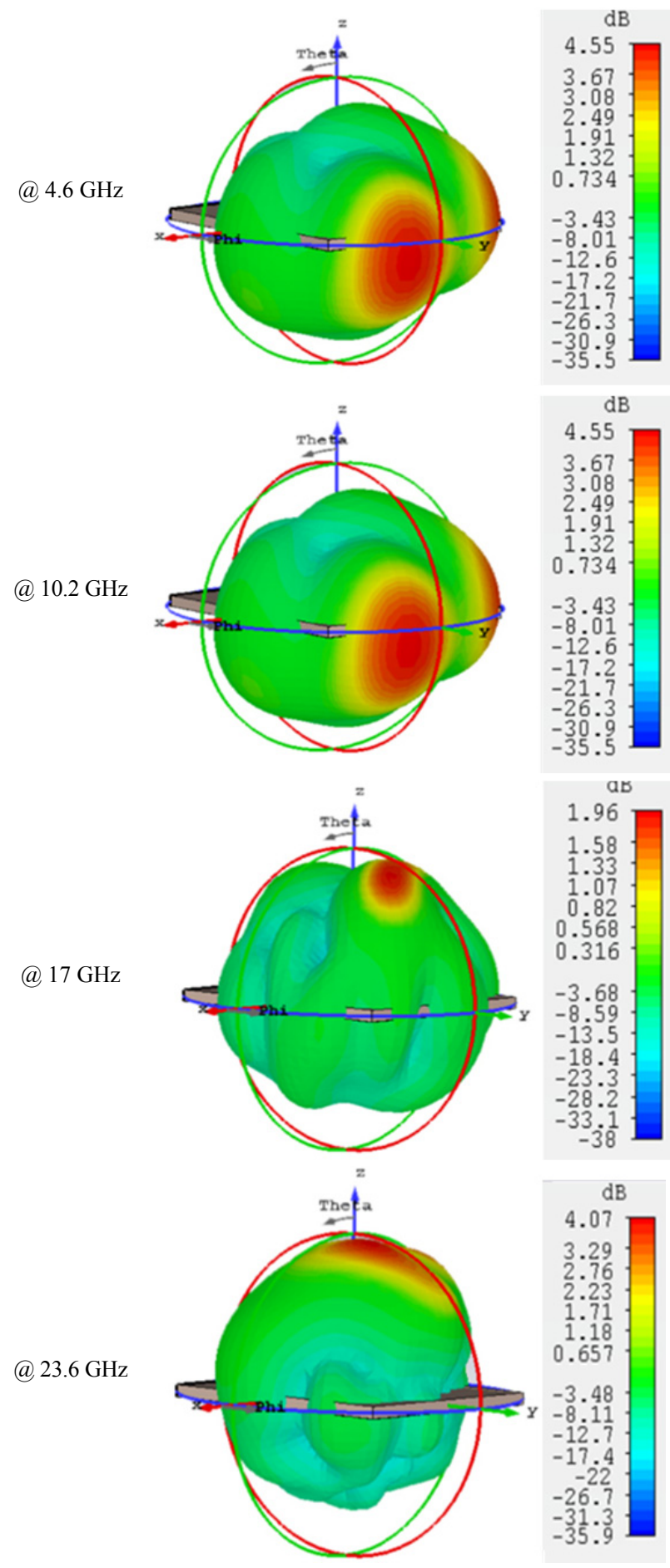

Fig. 8. 3-D radiation pattern at different frequencies within the band. 
The simulated and measured antenna gain and efficiency over the interested frequency band are plotted in Fig. 9(a) and (b), respectively by taking the step width of $0.2 \mathrm{GHz}$ frequency to provide an insight on the variations in gain as the frequency varied. The maximum realized gain obtained was about $6.2 \mathrm{~dB}$ at the frequency of 8.7 GHz. In fact, a substrate with lower permittivity and lower loss tangent than the substrate used in the present study would have provided further improved radiation properties in terms of gain and efficiency.

As it can be observed from Fig. 9(a), a negative gain at some frequencies is obtained; this can be explained in context: for fixed excitation, a constant amount of power is distributed to all frequency bands. Therefore, a sufficient amount of power is not there to excite different mode efficiently. Due to that reason, gain (and cross-pol level also) becomes low for the UWB antenna. The fact is that the gain bandwidth product for any antenna is a critical parameter. For a large gain, we should get narrow bandwidth and the reverse is true. So, we would not say there is a use for negative gain since we almost always want the most signal possible. But sometimes a negative gain is inevitable. However, gain is considered as one of many parameters that go into antenna design. Sometimes, we need antennas to be really small. Sometimes we need antennas to be lightweight. Or we need antennas to be highly directive, so they have positive gain in some directions but will have negative gain in other directions.

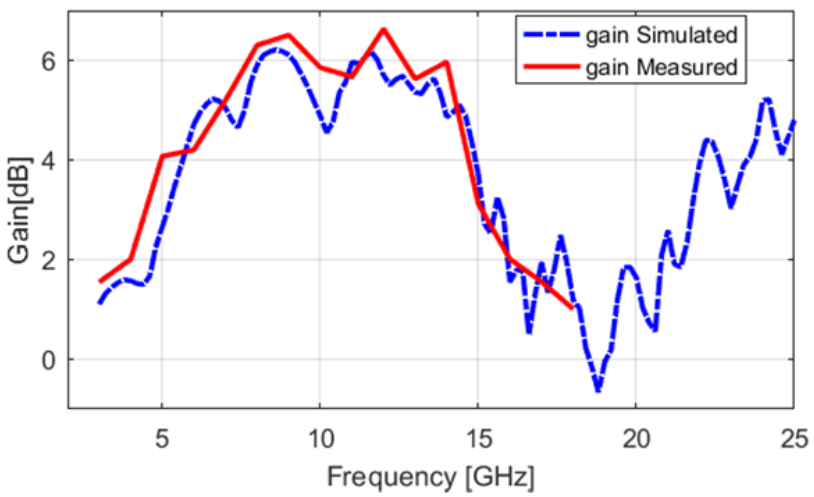

(a)

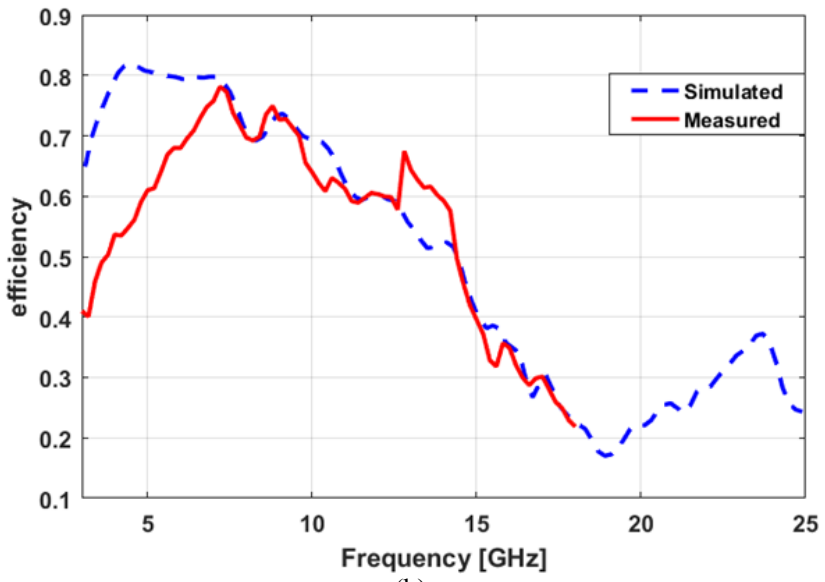

(b)

Fig. 9. Variation of (a) gain, and (b) efficiency with frequency.
To further verify the results derived from the $2 \mathrm{D}$ field pattern, the $y z$-plane and $x z$-plane at selected resonant frequencies for the proposed antenna are simulated and measured using the Satimo StarLab near-field antenna measurement setup ranging from $800 \mathrm{MHz}$ to $6 \mathrm{GHz}$ and from $6 \mathrm{GHz}$ to $18 \mathrm{GHz}$ as shown in Fig. 10. The measured Eand H-fields are displayed in Fig. 11. For the left-handed transmission characteristics of the metamaterial incorporated within the antenna, a monopole-like behavior of the antenna was observed at the lower frequencies. When the frequency increased, the radiation lobe split due to the higher-order modes. The presented result of the patch antenna highlights an advantageous characteristic in that it is able to transmit signals directionally for beam control.

As a final step to verify the proposed antenna in this paper, a comparison between this work and previous works from literature in terms of the antenna total occupation area, substrate used, bandwidth and antenna gain is summarized in Tab. 1. As it could be observed from the data reported in the table, the proposed antenna in this paper has small or comparable total area to the others. Although, this antenna is built on a non-expensive substrate, it has substantial gain and quite extended bandwidth wider than the others that considered in this comparison.
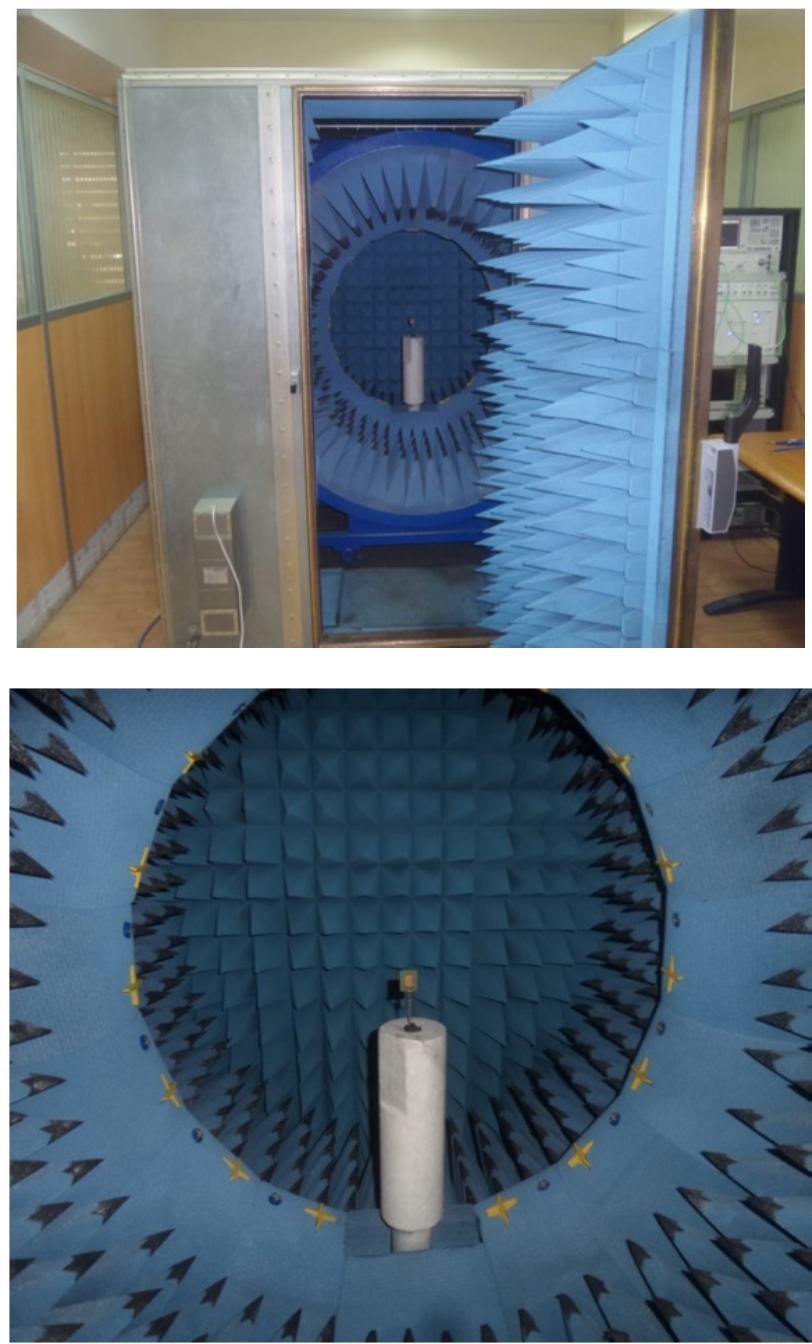

Fig. 10. Measurement setup in the Satimo StarLab at STCE, Cairo. 


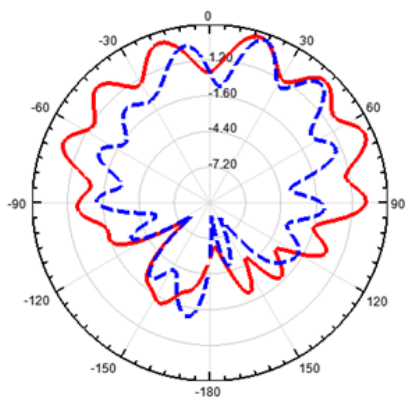

(a) $4.2 \mathrm{GHz}$

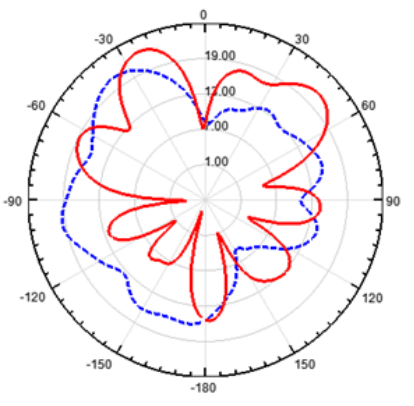

(a) $14.4 \mathrm{GHz}$

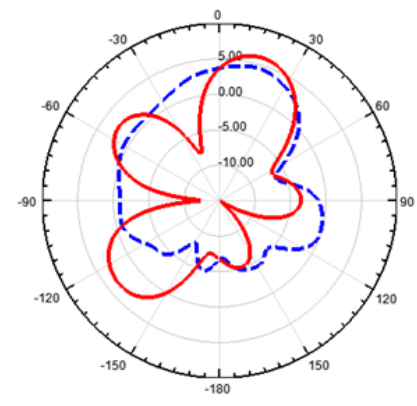

(a) $9.2 \mathrm{GHz}$

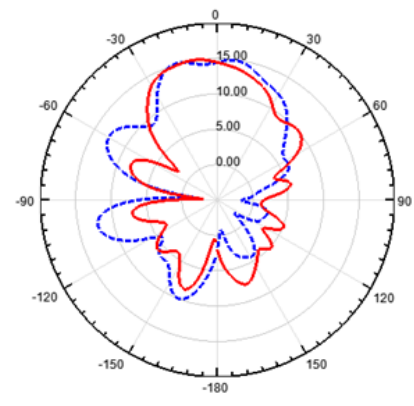

(a) $18 \mathrm{GHz}$
Fig. 11. Measured 2-D radiation pattern at the selected resonant frequencies.

\begin{tabular}{|c|c|c|c|c|}
\hline Ref. & Size $\left(\mathrm{mm}^{2}\right)$ & Substrate & $\begin{array}{c}\text { Bandwidth } \\
(\mathrm{GHz})\end{array}$ & $\begin{array}{c}\text { Gain } \\
(\mathrm{dB})\end{array}$ \\
\hline $\begin{array}{c}\text { This } \\
\text { work }\end{array}$ & $27.6 \times 32$ & $\begin{array}{c}\mathrm{FR} 4\left(\varepsilon_{\mathrm{r}}=4.5, \tan \delta\right. \\
=0.02, h=1.6 \mathrm{~mm})\end{array}$ & $3.2-23.9$ & 6.5 \\
\hline$[21]$ & $27.6 \times 31.8$ & $\begin{array}{c}\mathrm{FR} 4\left(\varepsilon_{\mathrm{r}}=4.5, \tan \delta\right. \\
=0.02, h=1.6 \mathrm{~mm})\end{array}$ & $3.3-17.4$ & 6.9 \\
\hline$[22]$ & $23 \times 24$ & $\begin{array}{c}\text { Rogers RT5880 } \\
\left(\varepsilon_{\mathrm{r}}=2.2, \tan \delta=\right. \\
0.0009, h=1.6 \mathrm{~mm})\end{array}$ & $3.9-8.2$ & 5.01 \\
\hline$[23]$ & $18.97 \times 27.17$ & $\begin{array}{c}\mathrm{FR} 4\left(\varepsilon_{\mathrm{r}}=4.6,\right. \\
h=1.6 \mathrm{~mm})\end{array}$ & $3.07-19.91$ & 8.5 \\
\hline$[24]$ & $28 \times 32$ & $\begin{array}{c}\mathrm{FR} 4\left(\varepsilon_{\mathrm{r}}=4.4,\right. \\
h=0.794 \mathrm{~mm})\end{array}$ & $3.3-12$ & 5.8 \\
\hline
\end{tabular}

Tab. 1. Comparison between this work and previous work.

\section{Conclusions}

The main objective of this work is to design and develop a compact, less complex UWB microstrip antenna which exhibits extended bandwidth. The design involves two important aspects, namely the 2D X-shaped periodic pattern on the radiating element and $2 \mathrm{D}$ periodic pattern of squares with cleft vertices in the ground plane. The proposed antenna has a wide $-10 \mathrm{~dB}$ impedance bandwidth, ranging from $3.2 \mathrm{GHz}$ to just over $24 \mathrm{GHz}$ (more than $170 \%$ ). The radiation characteristics of the antenna presented give maximum radiation in the plane of the patch and tend towards a directional radiation pattern as the frequency increases, thus producing high gain at the higher frequencies. The attained results have been thoroughly reviewed to validate the performance of the fabricated antenna. Measurement results were found to be in close agreement with the computer simulations. Compared to traditional UWB antennas, the proposed design is a good candidate for various UWB applications owing to its unique radiation characteristics.

\section{Acknowledgment}

Authors would like to thank Eng. Ahmed Abdelaziz at Luxor Higher Institute of Engineering \& Technology as well as Eng. Mohammed Saad at the Microwave Research Lab, STCE - Science \& Technology Center of Excellence, National Organization for Military Production, Cairo, Egypt for their help and support in carrying out the measurements.

\section{References}

[1] ELDEK, A. A., ELSHERBENI, A. Z., SMITH, C. E. Rectangular slot antenna with patch stub for ultra-wideband applications and phased array systems. Progress In Electromagnetic Research, 2005, vol. 53, p. 227-237. DOI: 10.2528/PIER04092701

[2] ALI, W., HAMAD, E. K. I., BASSIUNY, M. A., et al. Complementary split ring resonator based triple band microstrip antenna for WLAN/WiMAX applications. Radioengineering, 2017, vol. 26, no. 1, p. 78-84. DOI: 10.13164/re.2017.0078

[3] PUES, H. F., VAN DE CAPELLE, A. An impedance matching technique for increasing the bandwidth of microstrip antennas. IEEE Transactions on Antennas and Propagation, 1989, vol. 37, no. 11 , p. $1345-1354$. DOI: $10.1109 / 8.43553$

[4] ALI, W., IBRAHIM, A. A., MACHAC, J. Compact size UWB monopole antenna with triple band-notches. Radioengineering, 2017, vol. 26, no. 1, p. 57-63. DOI: 10.13164/re.2017.0057

[5] PARAMESWARAN A., SHUKLA, S. B., MUKUNDAN, K. K., et al. Bandwidth enhancement of microstrip patch antenna using metamaterials. IOSR Journal of Electronics and Communication Engineering (IOSR-JECE), 2013, vol. 8, no. 4, p. 05-10. DOI: $10.9790 / 2834-0840510$

[6] YABLONOVITCH, E. Inhibited spontaneous emission in solidstate physics and electronics. Physical Review Letters, 1987, vol. 58, no. 20, p. 2059-2062. DOI: 10.1103/PhysRevLett.58.2059

[7] JOHN, S. Strong localization of photons in certain disordered dielectric super-lattices. Physical Review Letters, 1987, vol. 58, no. 23, p. 2486-2489. DOI: 10.1103/PhysRevLett.58.2486

[8] YOUSEFI, L., MOHAJER-IRAVANI, B., RAMAHI, O. M. Enhanced bandwidth artificial magnetic ground plane for lowprofile antennas. IEEE Transaction Antennas and Wireless Propagation Letter, 2007, vol. 6, p. 289-292. DOI: 10.1109/LAWP.2007.895282

[9] COCCIOLI, R., YANG, F. R., MA, K. P., ITOH, T. Aperturecoupled patch antenna on UC-PBG substrate. IEEE Transactions on Microwave Theory and Techniques, 1999, vol. 47, no. 11, p. $2123-2130$. DOI: $10.1109 / 22.798008$

[10] SIEVENPIPER, D. F. High-impedance electromagnetic surfaces. Ph.D. Dissertation, Dept. of Electrical Engineering University of California, Los Angeles, CA, 1999.

[11] BOUTAYE, H., DENIDNI, T. A. Gain enhancement of a microstrip patch antenna using a cylindrical electromagnetic crystal sub- 
strate. IEEE Transactions on Antennas and Propagation, 2007, vol. 55, no. 11, p. 3140-3135. DOI: 10.1109/TAP.2007.908818

[12] ELSHEAKH, D. M. N., ELSADEK, H. A., ABDALLAH, E. A., et al. Ultra-wide bandwidth microstrip monopole antenna by using electromagnetic band-gap structures. Progress In Electromagnetics Research Letters, 2011, vol. 23, p. 109-118. DOI: 10.2528/PIERL11020805

[13] YANG, F., RAHMAT-SAMII, Y. Electromagnetic Band Gap Structures in Antenna Engineering. Cambridge University Press, 2008. DOI: $10.1017 /$ CBO9780511754531

[14] DAI, Y., YUAN, B., LUO, G., ZHANG, X. Ultra-wideband patch antenna with metamaterial structures. In IEEE 16th International Conference on Communication Technology (ICCT). Hangzhou (China), Oct. 2015. DOI: 10.1109/ICCT.2015.7399868

[15] XIONG H., HONG, J. S., ZHU, Q. Y., et al. Compact ultrawideband microstrip antenna with metamaterials. Chinese Physics Letters, 2012, vol. 29, no. 11., p. 1-3 DOI: 10.1088/0256$307 X / 29 / 11 / 114102$

[16] PANDEY, G. K., SINGH, H. S., BHARTI, P. K., et al. Metamaterial based compact antenna design for UWB applications. In IEEE Region 10 Symposium. Kuala Lumpur (Malaysia), 2014. DOI: 10.1109/TENCONSpring.2014.6862989

[17] LAMARI, S., KUBACKI, R., CZYZEWSKI, M. Bandwidth enhancement of a microstrip patch antenna using the metamaterial planar periodic structure. In Progress in Electromagnetics Research Symposium. Prague (Czech Republic), 2015, p. 330. ISBN: 978-1-5108-1561-2

[18] NADY, G., HAMAD, E. K. I. Design of compact UWB microstrip antenna using double-layer 2D periodic structure. IOSR Journal of Electronics and Communication Engineering (IOSR-JECE). Jul.Aug. 2018, vol. 13, no. 4, p. 76-84, Ver. I. DOI: 10.9790/28341304017684

[19] BANDLOW, B., SCHUHMANN, R., LUBKOWSKI, G., et al. Analysis of single-cell modeling of periodic metamaterial structures. IEEE Transactions on Magnetics, June 2008, vol. 44, no. 6, p. 1662-1665. DOI: 10.1109/TMAG.2007.916037

[20] ZIOLKOWSKI, R. W. Design, fabrication, and testing of double negative metamaterials. IEEE Transactions on Antennas and Propagation, 2003, vol. 51, no. 7, p. 1516-1529. DOI: 10.1109/TAP.2003.813622

[21] BAVISKAR, J., SHAH, A., MULlA, A., et al. Design and analysis of metamaterial lens incorporated ultra wide band (UWB) antenna. In IEEE Aerospace Conference. Montana (USA), March 2017, p. 1-6. DOI: 10.1109/AERO.2017.7943718

[22] ISLAM, M. M., ISLAM, M. T., SAMSUZZAMAN, M., et al. Compact metamaterial antenna for UWB applications. Electronics Letters, 2015 , vol. 51, no. 16, p. 1222-1224. DOI: 10.1049/el.2015.2131

[23] DAI, Y. L., YUAN, B., ZHANG, X. H., et al. A novel compact ultra-wideband metamaterial-based microstrip antenna. In IEEE MTT-S International Microwave Workshop Series on Advanced
Materials and Processes for RF and THz Applications (IMWSAMP). Chengdu (China), July 2016, p. 1-3. DOI: 10.1109/IMWSAMP.2016.7588421

[24] ALlen, B., DOHLER, M., OKON, E., et al. (Eds.) Ultra Wideband Antennas and Propagation for Communications, Radar and Imaging. Wiley-Blackwell, October 2006, p. 232. http://hdl.handle.net/10547/269813. ISBN: 9780470032558

\section{About the Authors...}

Ehab K. I. HAMAD earned his bachelor's and master's degrees in Electrical Engineering from Assiut University, Egypt in 1994 and 1999, respectively. He received his Ph.D. degree in Electrical Engineering from Otto-von-Guericke University Magdeburg, Germany in 2006. From 1996 to 2001 he was a Teaching/Research assistant at Aswan Faculty of Engineering, South Valley University. From July 2001 to December 2006, he was a Research Assistant at the Chair of Microwave and Communication Engineering, Otto-von-Guericke University Magdeburg, Germany. From July 2010 to April 2011, he joined the School of Computing and Engineering, University of Huddersfield, UK as a Post-doctoral Research Assistant. Dr. Hamad is currently an Associate Professor for microwave antennas at the Dept. of Electrical Engineering, Faculty of Engineering, Aswan University, Aswan, Egypt. Dr. Hamad has authored and co-authored over 40 technical peer reviewed papers in international journals and conference proceedings and he received 1 best paper award. His current research interests include the antenna design, MIMO antennas, mm-wave antennas, multiband/wideband small antennas for $4 \mathrm{G} / 5 \mathrm{G}$, metamaterials, UWB, and RFID. He is now designing microstrip antennas for $5 \mathrm{G}$ wireless communications using characteristics mode analysis.

Gehad NADY was born in Aswan, Egypt in 1991. She received her B.Sc. in Electrical Engineering from Arab Academy for Science, Technology and Maritime Transport, Aswan, Egypt, in 2013. She earned her Master Degree in Electrical Engineering from the Faculty of Engineering, Aswan University in November 2018. Her current research interests include the antenna design, microstrip patch antennas, UWB, and metamaterials. 